\title{
Proposição de graus de não congruência semântica nas conversões entre os registros geométrico bidi- mensional e o simbólico fracionário dos números ra- cionais
}

\author{
Fernanda Andrea F. Silva \\ (iD) \\ Instituto Federal da Paraíba \\ Ð fernanda.silva@ifpb.edu.br \\ Marcelo Câmara dos \\ Santos (iD \\ Universidade Federal de \\ Pernambuco
}

వmarcelocamaraufpe@yahoo.com.br

\author{
Proposition of degrees of no-semantic congruence in the \\ conversions between two-dimensional geometric registers and the \\ fractional symbolic of rational numbers
}

\begin{abstract}
The study is a theoretical proposition that aimed to categorize, in degrees of nonsemantic congruence, the conversions between two-dimensional geometric registers and the fractional symbolic of rational numbers, being a clipping of the doctoral thesis of [17]. For this we adopt as categories of analysis a classification of the semiotic representations belonging to the two-dimensional geometric register; the figurative units, which were defined from the variables, visual, dimensional and qualitative; the types of geometric seizures required by the geometric figures at the time of conversion; the symbolic units of the arrival register and the criteria of semantic congruence. The proposed categorization relies on six degrees of non-semantic congruence in the conversions between two-dimensional and symbolic fractional symbolic registers of rational numbers.
\end{abstract}

Key words: Conversions; Geometric Two-Dimensional; Symbolic Fractional; Semiotics; Non-Semantic Congruence.

\begin{abstract}
Resumo
O estudo trata de uma proposição teórica que teve como objetivo categorizar, em graus de não congruência semântica, as conversões entre os registros geométrico bidimensional e o simbólico fracionário dos números racionais, sendo um recorte da tese de doutorado da autora. Para tal adotamos como categorias de análise uma classificação das representações semióticas pertencentes ao registro geométrico bidimensional; as unidades figurais, que foram definidas a partir das variáveis visuais, dimensionais e qualitativas; os tipos de apreensões geométricas requeridas pelas figuras geométricas, no momento da conversão; as unidades simbólicas do registro de chegada e os critérios de congruência semântica. A categorização proposta conta com seis graus de não congruência semântica nas conversões entre os registros geométrico bidimensional e simbólico fracionário dos números racionais.

Palavras-chave: Conversões, Geométrico Bidimensional, Simbólico Fracionário, Semiótica, não Congruência Semântica
\end{abstract}




\section{INTRODUÇÃO}

O registro geométrico bidimensional dos números racionais ${ }^{1}$ é usado prioritariamente na escola para trabalhar o significado parte-todo [3, 5, 14, 15], sendo fundamental para a construção dos demais significados dos números racionais e, consequente, desenvolvimento conceitual [1]; além de ser gerador da linguagem nesse campo numérico [11].

Conforme [5], a representação semiótica do número racional, com o significado parte-todo, precisa ser compreendida pelo sujeito de tal forma a indicar os elementos que representam o todo, os elementos que representam as partes e como esses se relacionam. $\mathrm{O}$ autor afirma que duas são as formas predominantes da representação semiótica do significado parte-todo dos números racionais, a simbólica fracionária, a/b, pois diferem dos outros números os quais os sujeitos se deparam; e a geométrica, 'regiões', na maioria das vezes, representadas em retângulos ou círculos, que necessitam da compreensão de medidas para o reconhecimento das partes do todo representadas por figuras geométricas congruentes, ou particionamento do 'todo' em figuras com áreas congruentes. Além disso é necessário identificar o 'todo'. Portanto, sendo então necessárias diferentes estruturas cognitivas para identificar a relação entre "a área correspondente à parte hachurada e a área total da figura" [5] (p. 69).

Ademais, as conversões realizadas entre o registro geométrico bidimensional e o simbólico fracionário dos números racionais, submetem-se a influências dos tipos de interpretações, denominadas por [6, 7] de 'apreensões geométricas', que os elementos básicos constituintes das figuras geométricas, ou 'unidades figurais' demandam, para serem visualizadas.

Ao trabalharem com distratores ${ }^{2}$ visual-perceptuais em atividades com lápis e papel, entre sujeitos de $4^{\mathrm{a}}$ série do Ensino Fundamental, envolvendo conversões entre registros de representações semióticas dos números racionais, tendo como registro de partida, o geométrico bidimensional (denominado na pesquisa por quantidades contínuas), ou o figural (quantidades discretas), ou o geométrico unidimensional (as retas numéricas); e como registro de chegada, o simbólico fracionário; observaram que os sujeitos apresentam níveis diferentes de capacidades para ignorar os distratores e lidar com as tarefas em nível lógico-matemático [2]. Os distratores foram classificados em 'consistentes com a tarefa', 'irrelevantes' e 'inconsistentes com a tarefa'. No caso do registro geométrico bidimensional, as figuras geométricas 'consistentes' possuíam o particionamento, explícito, necessário para a conversão no registro simbólico fracionário; as 'irrelevantes', necessitavam que o sujeito ignorasse algumas divisões do par-

\footnotetext{
${ }^{1}$ Denominamos registro geométrico dos números racionais aquele cujas representações são figuras geométricas planas.

${ }^{2}$ São informações visuais-perceptuais inconsistentes com a solução buscada.
} 
ticionamento explícito para a conversão; e as representações 'inconsistentes', que o sujeito desprezasse todo o particionamento explícito da figura geométrica. E apontam como um dos fatores importantes na compreensão do conceito de número racional, a capacidade do sujeito de resolver os conflitos entre o processamento perceptual das informações visuais e o cognitivo das relações lógico-matemáticas.

Corroboramos com as ideias dos autores no sentido de entender que as informações visual-perceptuais podem favorecer ou dificultar as transformações entre o registro geométrico bidimensional e o simbólico fracionário dos números racionais. Pois, nelas estão presentes os elementos característicos básicos ou 'unidades de sentido figurais' [8] do registro de partida necessários à conversão, podendo se fazerem totalmente explícitos, e então a conversão se assemelharia a uma 'codificação', ou pelo contrário, necessitarem serem encontrados, o que demandaria ir além dos elementos perceptivos e operar heuristicamente a representação.

Compreendemos que quanto menos 'transparecem' os elementos figurais que estabelecem a relação parte-todo na representação geométrica a ser convertida para o registro simbólico fracionário mais elementos figurais deverão ser 'descobertos' ou colocados de forma 'explícita', o que leva a diferentes graus de não congruência semântica na conversão entre esses registros. Dessa forma, desenvolvemos uma análise teórica das conversões que tiveram como registro de partida o geométrico bidimensional e como registro de chegada o simbólico fracionário dos números racionais e propomos uma classificação dessas conversões em seis graus de não congruência semântica. Para tal, tivemos como base, (a) uma classificação para as figuras geométricas pertencentes ao registro geométrico bidimensional, desenvolvida em nosso estudo; além das outras categorias de análise: (b) unidades figurais - definidas a partir das variáveis, visuais - dimensionais e qualitativas [7]; (c) tipos de apreensões geométricas $[6,7,8]$ requeridas pelas figuras geométricas do registro de partida, no momento da conversão; (d) as unidades simbólicas do registro de chegada; (e) os critérios de congruência semântica definidos em [7, 8], correspondência semântica entre as unidades de sentido e univocidade semântica terminal. O terceiro critério de congruência semântica definido por [7, 8], 'mesma ordem das unidades de sentido', não foi considerado em nosso estudo, por não ser aplicável, pois o registro geométrico bidimensional, como registro de partida, não necessariamente determina uma ordem de escrita no registro de chegada.

A seguir traremos a discussão dos seis graus de não congruência semântica nas conversões entre os registros geométrico bidimensional e simbólico fracionário dos números racionais. 


\section{GRAU 1 DE NÃO CONGRUÊNCIA SEMÂNTICA}

Nesse nível estarão as conversões que envolvem as figuras perceptuais que representam um inteiro. Denominamos figuras perceptuais os polígonos, círculos, correspondentes a um ou mais inteiros, contínuo(s), particionado(s) - com todas as demarcações internas de divisão explícitas - em áreas congruentes e formas ${ }^{3}$ homogêneas, justapostas, sendo algumas delas pintadas ou hachuradas, conforme Quadro 1.

Quadro 1- Figuras perceptuais.

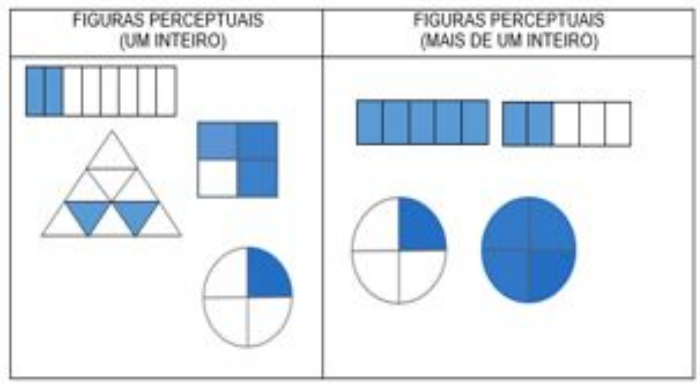

Fonte: [17] (p. 79)

Nesse tipo de conversão, segundo [19], o sujeito necessita identificar no registro geométrico as partes congruentes ${ }^{4}$ que formam o todo, e aquelas destacadas; realizar a dupla contagem, a das partes congruentes do todo e a das partes destacadas; e representar no registro simbólico fracionário o resultado da contagem. Acima do traço de fração estará o valor numérico correspondente ao da contagem das partes destacadas e, abaixo do traço de fração, o valor numérico equivalente à contagem das partes que compõem o todo. Por não ser preciso fazer qualquer modificação na figura, nos leva a afirmar que requer do sujeito uma apreensão do tipo perceptual, conforme [10], bem como uma apreensão discursiva entre as unidades figurais e as simbólicas, no registro simbólico fracionário.

As unidades figurais do registro de partida envolvendo figuras perceptuais, as quais compreendemos influenciar na conversão para o registro simbólico fracionário, são sete, sendo, uma unidimensional, as demarcações internas de divisão do todo, contínuo, em partes congruentes justapostas; uma unidade figural bidimensional, as áreas congruentes das partes ou subfiguras que compõem o todo; além das unidades figurais qualitativas, cor ou hachuramento de algumas das partes ou subfiguras do todo, ausência de cor, formas homogêneas das subfiguras, quantitativo das partes com cor e quantitativo das partes com cor e ausência de cor. Enquanto que as unidades de sentido do registro de chegada são o número natural, que representa o numerador, o traço de fração e o número natural diferente de zero que representa o denominador.

\footnotetext{
${ }^{3} \mathrm{~A}$ partir de agora iremos nos referir as formas geométricas das partes ou subfiguras, por 'formas'.

${ }^{4}$ Consideramos partes congruentes aquelas que possuem áreas congruentes e formas homogêneas.
} 
Essas unidades de sentido no registro de chegada não se alteram para todos os graus aqui analisados.

As demarcações internas de divisão do todo, contínuo, em partes congruentes justapostas se correspondem semanticamente, de forma 'simples', com o traço de fração, no registro de chegada. Consideramos uma correspondência 'simples' porque uma unidade figural, as demarcações internas de divisão do todo se correspondem com uma unidade simbólica, o traço de fração, no registro de chegada. Pois, o traço de fração significa uma relação entre as partes congruentes de um todo e esse todo. As demarcações internas de divisão favorecem a visualização das partes congruentes do todo.

As unidades figurais, áreas das partes ou subfiguras congruentes, formas homogêneas das partes ou subfiguras, cor e quantidade total de partes ou subfiguras com cor ou hachuramento, se correspondem semanticamente de forma combinada ${ }^{5}$ com o numerador da fração. Enquanto que as unidades figurais áreas congruentes das partes ou subfiguras, formas homogêneas das partes ou subfiguras, cor, ausência de cor e quantidade total de partes ou subfiguras com cor e ausência de cor do todo se correspondem semanticamente com o denominador da fração. A Figura 1 é um exemplo da análise da conversão envolvendo esse tipo de figura.

Figura 1: Esquema relativo a conversão de não congruência semântica entre uma figura perceptual de um inteiro do registro geométrico bidimensional dos números racionais e a representação simbólica no registro simbólico fracionário.

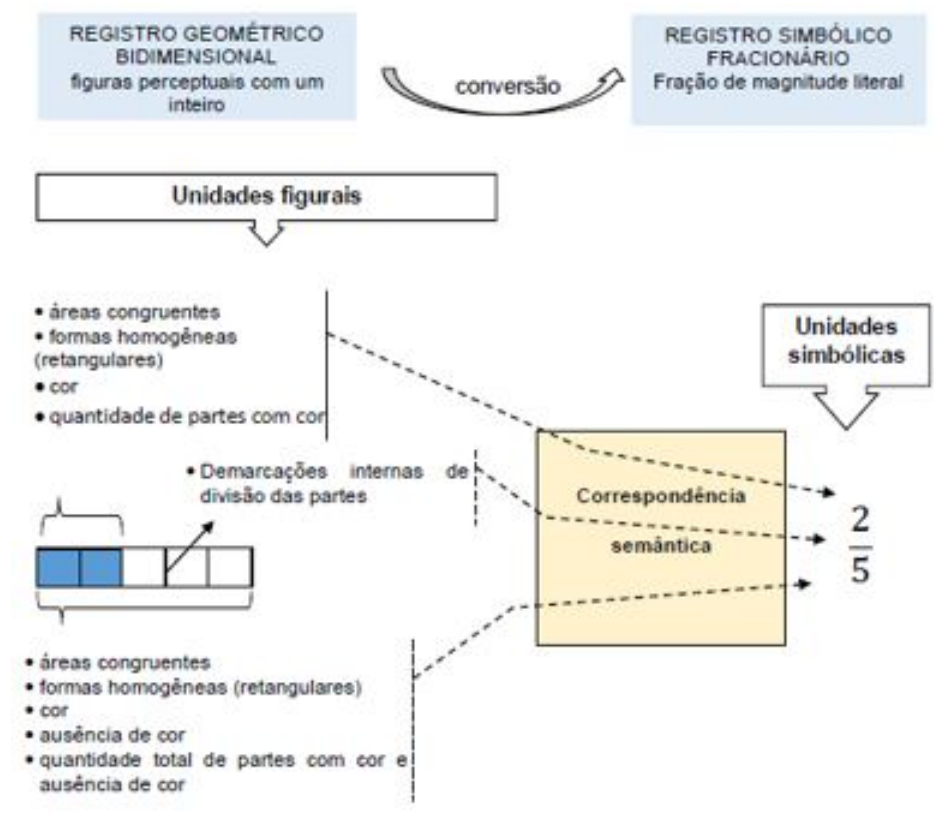

Fonte: [17] (p. 101)

\footnotetext{
${ }^{5}$ Correspondência de forma combinada é quando há mais de uma unidade significante no registro de partida se relacionando com uma unidade significante no registro de chegada.
} 
Áreas congruentes, formas homogêneas e cor são unidades figurais consideradas tanto para a correspondência semântica com a unidade simbólica numerador, quanto para o denominador, como ilustrado na Figura 1. Portanto, o critério de congruência semântica "univocidade semântica terminal" é obedecido apenas entre a unidade figural, demarcações internas de divisão do todo, no registro de partida, e a unidade de significado traço de fração, no registro de chegada, pois uma unidade figural se corresponde com uma única unidade no registro de chegada. Como também, entre as unidades figurais, ausência de cor e quantidade de partes ou subfiguras com cor e ausência de cor do todo, e o denominador da fração.

Como o critério de univocidade semântica terminal não é observado para todas as correspondências semânticas entre as unidades de sentido, inferimos, de acordo com [7], que não há congruência semântica na conversão entre esses registros, envolvendo as figuras perceptuais com um inteiro, no registro de partida.

Acreditamos que é a não congruência semântica que leva os sujeitos a erros do tipo 'relação parte-parte', apontados pelas pesquisas de $[12,16]$ como sendo erros frequentes, em que o sujeito em tarefas que necessitam desse tipo de conversão, realizam a contagem das partes ou subfiguras hachuradas para o valor do numerador e das partes ou subfiguras não hachuradas para o denominador. A conversão, ao ser realizada erroneamente dessa forma, preserva o critério da univocidade semântica terminal para a correspondência entre a unidade figural, cor e o valor correspondente ao numerador da fração e entre a unidade figural ausência de cor e o denominador da fração. Dessa forma, favorece a percepção de uma congruência semântica, sem que haja a equivalência referencial. Como afirma [9], o funcionamento espontâneo do pensamento tende a manter a congruência semântica. Os sujeitos que se prendem apenas a ela são aqueles em que os aspectos visuais sobrepõem aqueles lógico-matemáticos.

\section{GRAU 2 DE NÃO CONGRUÊNCIA SEMÂNTICA}

Nesse nível de não congruência semântica estarão as conversões que envolvem as figuras perceptuais que representam mais de um inteiro, como registro de partida.

Essas conversões requerem do sujeito, uma apreensão perceptual e discursiva entre as unidades figurais dos registros envolvidos. Entretanto, o procedimento da dupla contagem para a conversão no registro simbólico fracionário utilizado com as figuras perceptuais, neste caso, em que temos mais de um inteiro, pode se mostrar menos "evidente". Pois, a unidade simbólica denominador, requer que o sujeito realize uma apreensão discursiva entre ela e a unidade figural, 'inteiro'. Uma leitura perceptual ou gestáltica das formas, sem essa apreensão discursiva, pode levar a uma contagem de todas as subfiguras ou partes dos todos, como tratando-se apenas de um inteiro.

As unidades figurais do registro de partida são sete, sendo: uma unidimensional, as 
demarcações internas de divisão do todo, contínuo, em partes ou subfiguras congruentes justapostas; uma unidade figural bidimensional, as áreas congruentes das partes ou subfiguras que compõem os todos; além das unidades figurais qualitativas, cor ou hachuramento das partes ou subfiguras dos todos, ausência de cor, formas geométricas homogêneas das subfiguras, quantitativo total das partes ou subfiguras com cor dos todos e quantitativo total das partes ou subfiguras de um inteiro. As demarcações de divisão do todo, contínuo, em partes congruentes justapostas se correspondem semanticamente de forma simples, ou seja, diretamente com o traço de fração, no registro de chegada. Há uma correspondência semântica, de forma combinada, das unidades figurais: áreas congruentes das partes ou subfiguras, formas das partes ou subfiguras homogêneas, cor e quantidade total de partes ou subfiguras com cor ou hachuramento dos todos, no registro de partida, com o numerador da fração, no registro de chegada. O mesmo ocorre com as unidades figurais, áreas congruentes das partes ou subfiguras de um inteiro, formas das partes ou subfiguras homogêneas de um inteiro, quantidade total das partes ou subfiguras de um inteiro com o denominador da fração.

A unidade figural quantidade total das partes ou subfiguras com cor e ausência de cor não se corresponde semanticamente com a unidade simbólica, denominador da fração, no registro de chegada; pois no registro de partida teremos mais de 'um inteiro'. Assim como as unidades figurais cor e ausência de cor não irão corresponderse semanticamente com o denominador, pois, dependendo do inteiro considerado, ele poderá ter todas as partes ou subfiguras com cor ou não, conforme Figura 2. 
Figura 2: Esquema relativo a conversão entre uma figura perceptual com mais de um inteiro do registro geométrico bidimensional dos números racionais e sua representação simbólica no registro simbólico fracionário.

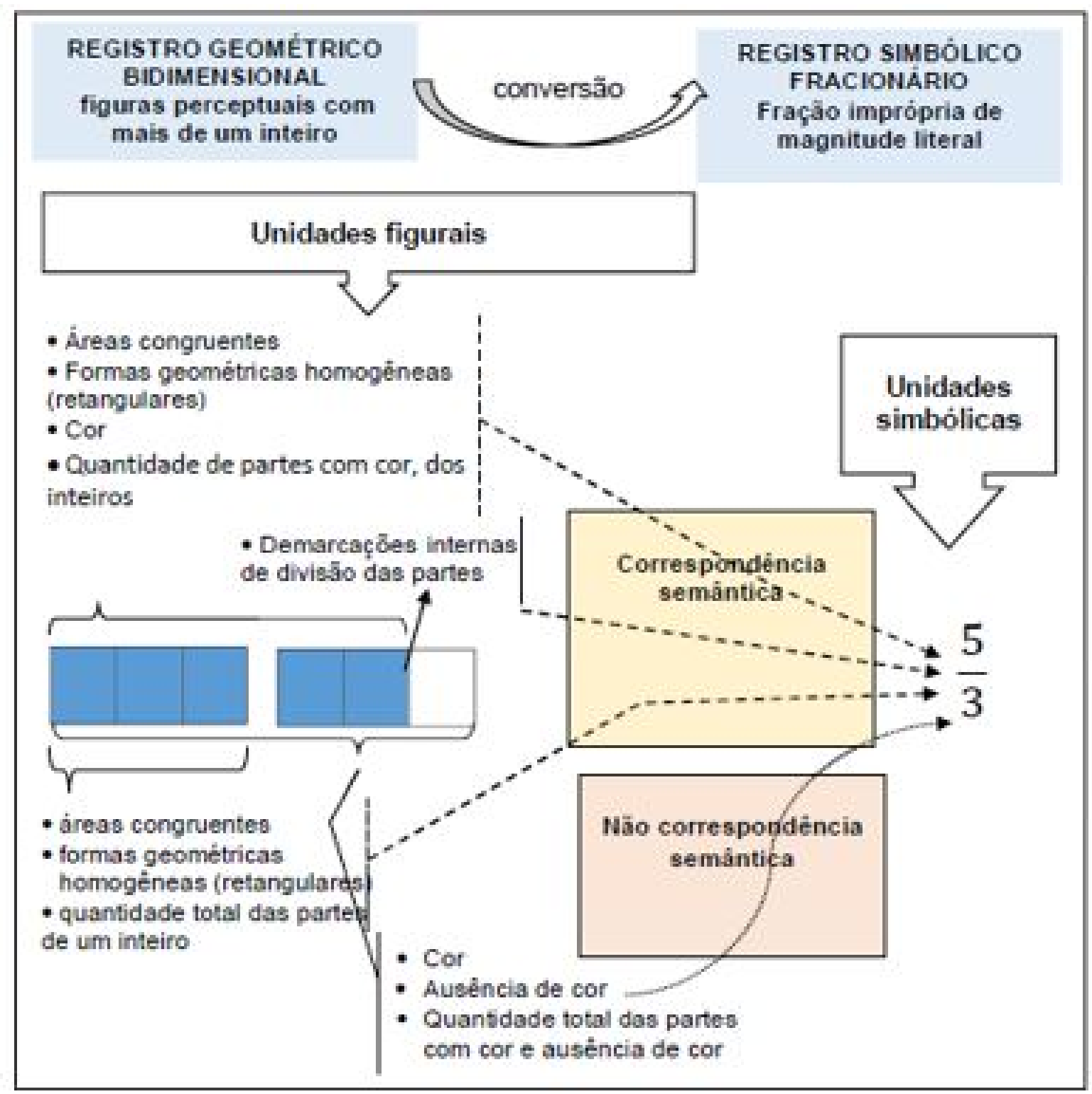

Fonte: [17] (p. 105)

Quanto ao critério, univocidade semântica terminal, ele é obedecido entre as demarcações de divisão, no registro de partida, e o traço de fração, no registro de chegada; entre as unidades figurais cor, quantidade das partes ou subfiguras com cor dos inteiros e a unidade simbólica, numerador; e entre as unidades figurais, quantidade total das partes ou subfiguras de um inteiro e a unidade simbólica, denominador. Como podemos observar na Figura 2.

Compreendemos que a não correspondência semântica que ocorre entre a unidade figural, quantidade total das partes ou subfiguras com cor e ausência de cor; e a 
unidade simbólica denominador da fração, pode ter relação com os erros comumente realizados pelos alunos que relacionam o denominador da fração com a quantidade total de partes dos todos, ou seja, não reconhecem o todo, como referencial, como aponta [13]. Pois, apesar dessas unidades, figural e simbólica, não terem equivalência referencial elas são semanticamente congruentes ao método da dupla contagem, "quantidade total de partes" para o denominador, levando à perda do inteiro como referencial.

\section{GRAU 3 DE NÃO CONGRUÊNCIA SEMÂNTICA}

Nesse nível estarão as conversões que envolvem as figuras operatórias por inclusão das partes ou subfiguras, como registro de partida. As figuras operatórias por inclusão das partes são polígonos, círculos, correspondentes a um inteiro, contínuo, particionado - com todas as demarcações internas de divisão explícitas - em áreas congruentes e formas homogêneas, justapostas, sendo algumas delas pintadas ou hachuradas, onde o número de partes pintadas pode ser relocadas como uma nova unidade de medida, permitindo assim, uma reconfiguração das partes que foi dividido o todo, conforme a Figura 3:

Figura 3: Figuras operatórias por inclusão das partes.

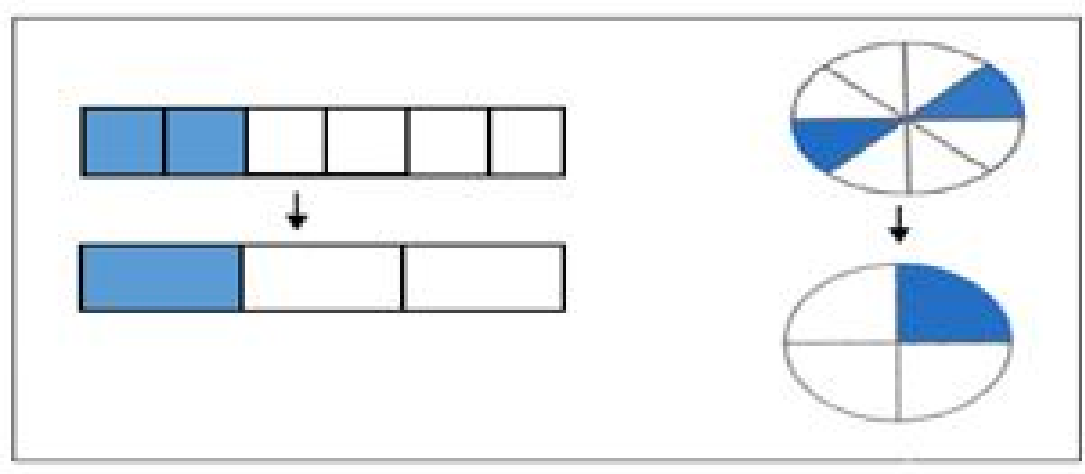

Fonte: [17] (p. 80)

Nesse grau de não congruência semântica as figuras geométricas, representações do registro de partida, além das apreensões, perceptual e discursiva, podem receber um tratamento figural, para que a conversão no registro simbólico fracionário resulte numa fração irredutível.

Dessa forma, as conversões nesse nível favorecem o desenvolvimento do conceito de equivalência, por meio da apreensão operatória. A operação de reconfiguração intermediária permitirá ao sujeito visualizar no registro simbólico fracionário, além da fração de magnitude literal, uma fração de magnitude relativa, ou seja, equivalente à apreendida perceptualmente na figura inicial.

As unidades figurais do registro de partida são sete, sendo uma unidimensional, 
as demarcações internas de divisão do todo, contínuo, em partes ou subfiguras congruentes justapostas; uma unidade figural bidimensional, as áreas congruentes das partes ou subfiguras que compõem o todo; as unidades figurais qualitativas, cor ou hachuramento das partes ou subfiguras do todo, ausência de cor, formas geométricas homogêneas das partes ou subfiguras, quantitativo total das partes ou subfiguras com cor do todo e quantitativo das partes ou subfiguras com cor e ausência de cor, conforme Figura 4.

Figura 4: Esquema relativo à análise da conversão entre uma figura operatória por inclusão das partes do registro geométrico bidimensional dos números racionais e uma fração de magnitude relativa no registro simbólico fracionário.

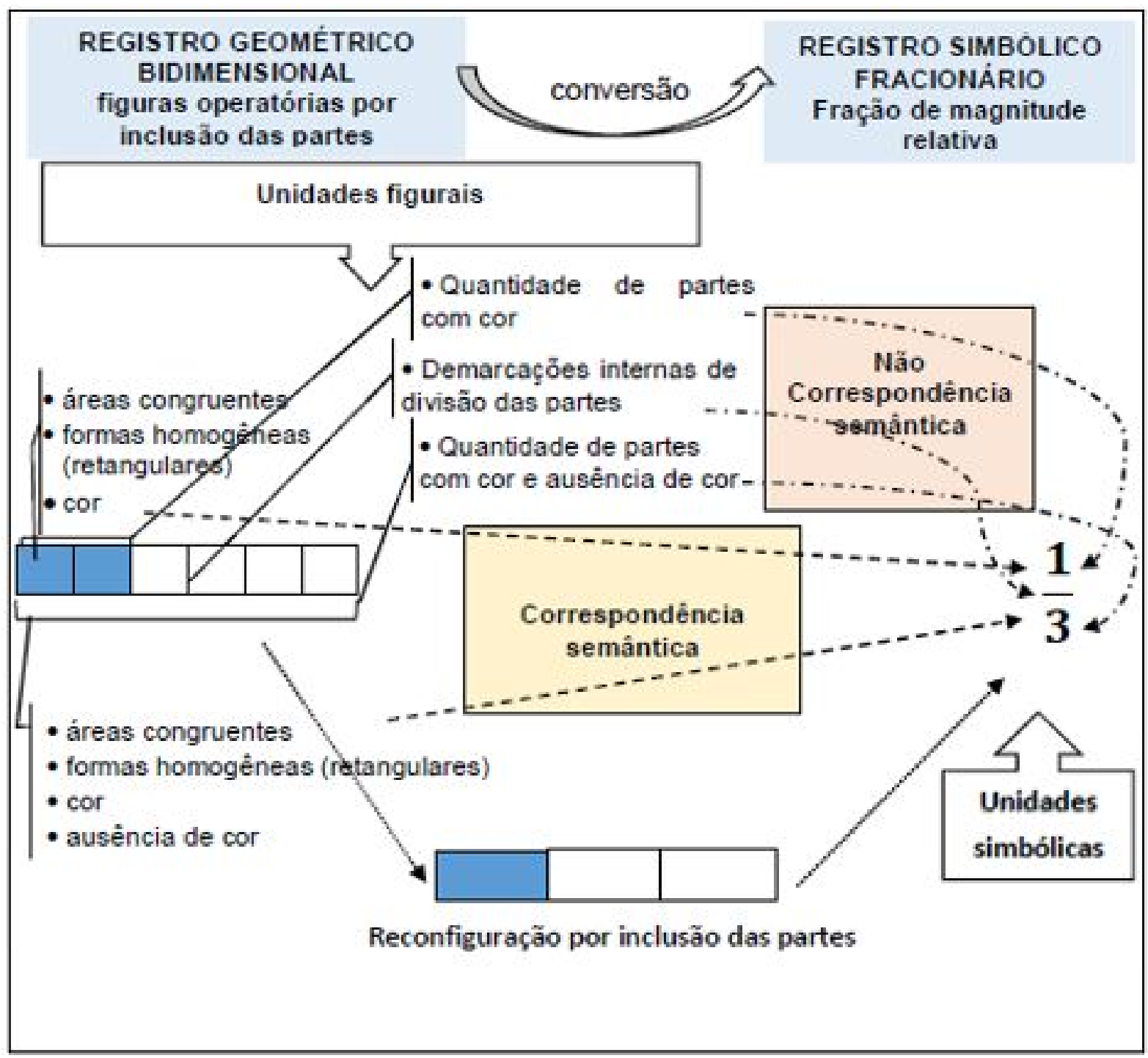

Fonte: [17] (p. 108)

De acordo com a Figura 4, há uma correspondência semântica, de forma combinada, das unidades figurais, áreas congruentes das partes ou subfiguras, formas geométricas das partes ou subfiguras homogêneas e cor, no registro de partida, com 
o numerador da fração, no registro de chegada. O mesmo ocorre com as unidades figurais, áreas congruentes das partes ou subfiguras, cor, ausência de cor e formas geométricas homogêneas das partes ou subfiguras com o denominador da fração.

A unidade figural quantidade das partes ou subfiguras com cor não se corresponde semanticamente com a unidade simbólica, numerador da fração, no registro de chegada; pois o numerador da fração corresponderá ao quantitativo de partes ou subfiguras após o tratamento de reconfiguração por inclusão das partes ou subfiguras da figura inicial. Da mesma forma ocorrerá com a unidade figural, quantitativo de cor e ausência de cor da figura inicial, e o denominador da fração, no registro de chegada. As demarcações internas de divisão do todo não irão corresponder-se semanticamente com o traço de fração, pois a relação das partes com o todo que é estabelecida na figura inicial não é a mesma entre o numerador e o denominador da fração.

Quanto ao critério univocidade semântica terminal, ele é obedecido entre as demarcações internas de divisão do todo, no registro de partida e o traço de fração, no registro de chegada. Apesar da correspondência semântica entre essas unidades de sentido ocorrerem apenas após o tratamento figural, as demarcações internas de divisão do todo, no registro de partida se correspondem unicamente com o traço de fração, no registro de chegada. O mesmo ocorre entre as unidades figurais, quantidade com cor e ausência de cor e a unidade simbólica, denominador. As unidades figurais, áreas congruentes das partes ou subfiguras, formas geométricas homogêneas das partes ou subfiguras, cor e quantidade de partes ou subfiguras com cor no registro de partida, não satisfazem o critério da univocidade semântica terminal, pois se correspondem ao mesmo tempo com duas unidades simbólicas, no registro de chegada, numerador e denominador.

[4] apontam para o uso frequente do procedimento da 'dupla contagem' nessas conversões, que envolvem as figuras operatórias por inclusão das partes, as quais obtém como resultados frações de magnitude literal e a não compreensão, por parte de muitos sujeitos que se utilizam desse procedimento, da equivalência, entre as frações de magnitude literal e relativa.

A conversão que transforma uma figura operatória por inclusão das partes numa fração, de magnitude literal, requer do sujeito, apenas, uma apreensão perceptual e discursiva das unidades elementares entre os registros, como no grau 1 de não congruência semântica, portanto, não favorece ao desenvolvimento do conceito de equivalência.

A operação de reconfiguração intermediária global, explícita ou não, é necessária para reduzir proporcionalmente o número de partes ou subfiguras da figura inicial, por meio da inclusão de partes ou subfiguras justapostas de formas geométricas homogê- 
neas e áreas congruentes. A figura obtida terá um número menor de partes ou subfiguras, de mesma forma geométrica que as iniciais, entretanto, com áreas congruentes das partes ou subfiguras equivalentes às anteriores. Os elementos figurais facilitadores da operação de reconfiguração das figuras operatórias por inclusão das partes ou subfiguras são a simetria, homogeneidade das formas e congruência das áreas das subfiguras ou partes, pois podem favorecer a percepção de uma nova unidade-parte ${ }^{6}$, equivalente à anterior, e a consequente modificação da figura inicial por inclusão das partes ou subfiguras.

\section{GRAU 4 DE NÃO CONGRUÊNCIA SEMÂNTICA}

Nesse nível de não congruência semântica estarão as conversões que envolvem as figuras operatórias por divisão, como registro de partida. Esses tipos de figuras dificultam a apreensão da unidade-parte. As figuras operatórias por divisão são polígonos, círculos, correspondentes a um inteiro, contínuo, particionado - tendo algumas demarcações internas de divisão implícitas - em áreas explícitas diferentes e formas homogêneas, justapostas, sendo algumas delas pintadas ou hachuradas. Foram assim denominadas, por necessitarem de um tratamento, explícito ou não, de descoberta da unidade-parte e da divisão em partes ou subfiguras congruentes para que seja interpretada a relação entre as partes ou subfiguras hachuradas e o todo, conforme Figura 5.

Figura 5: Figuras operatórias por divisão.

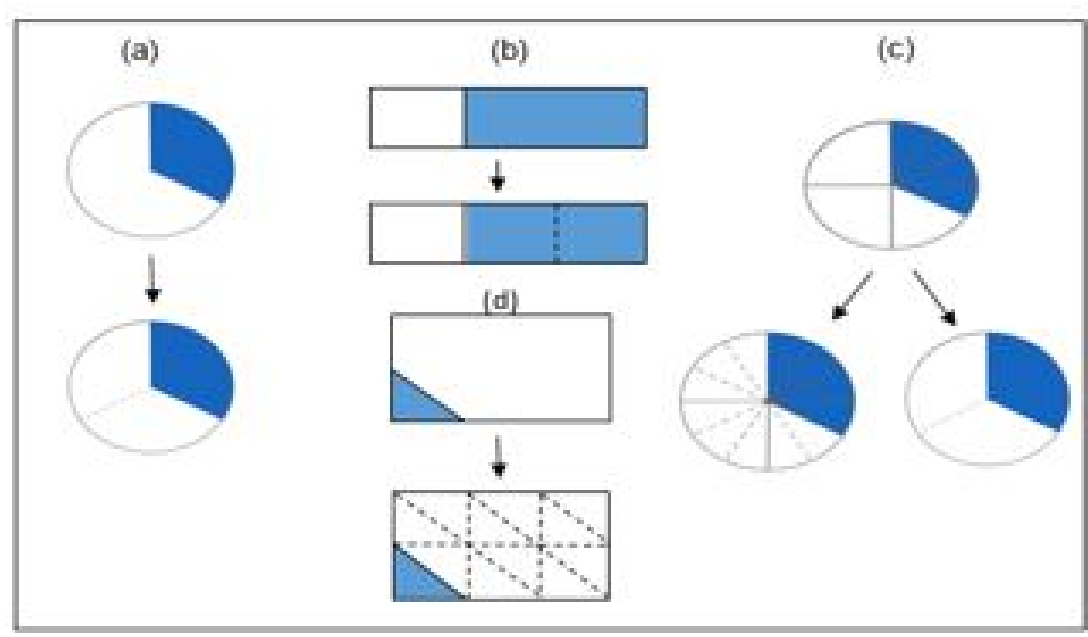

Fonte: [17] (p. 82)

Nesse grau, a conversão requer do sujeito, além das apreensões, perceptual e discursiva das unidades figurais, uma apreensão operatória de reconfiguração, explícita ou não, para divisão em partes ou subfiguras de áreas explícitas congruentes e formas

\footnotetext{
${ }^{6}$ Unidade-parte é a subfigura referência para a divisão do todo em partes congruentes. O quantitativo total dessas subfiguras equivalem ao inteiro.
} 
geométricas homogêneas. Esse tratamento permitirá ao sujeito visualizar as parte ou subfiguras de áreas congruentes formas geométricas homogêneas, possibilitando a compreensão da relação parte-todo e a conversão no registro simbólico fracionário.

As unidades figurais do registro de partida são sete, sendo uma unidimensional, as demarcações internas de divisão do todo, contínuo, em partes ou subfiguras justapostas; uma unidade figural bidimensional, as áreas explícitas diferentes das partes ou subfiguras que compõem o todo inicial; as unidades figurais qualitativas, cor ou hachuramento das partes ou subfiguras do todo, ausência de cor, formas geométricas homogêneas das partes ou subfiguras, quantitativo total das partes ou subfiguras com cor e quantitativo das partes ou subfiguras com cor e ausência de cor, conforme Figura 6.

Figura 6: Esquema relativo à análise da conversão entre uma figura operatória por divisão do registro geométrico bidimensional dos números racionais e uma fração própria de magnitude literal no registro simbólico fracionário.

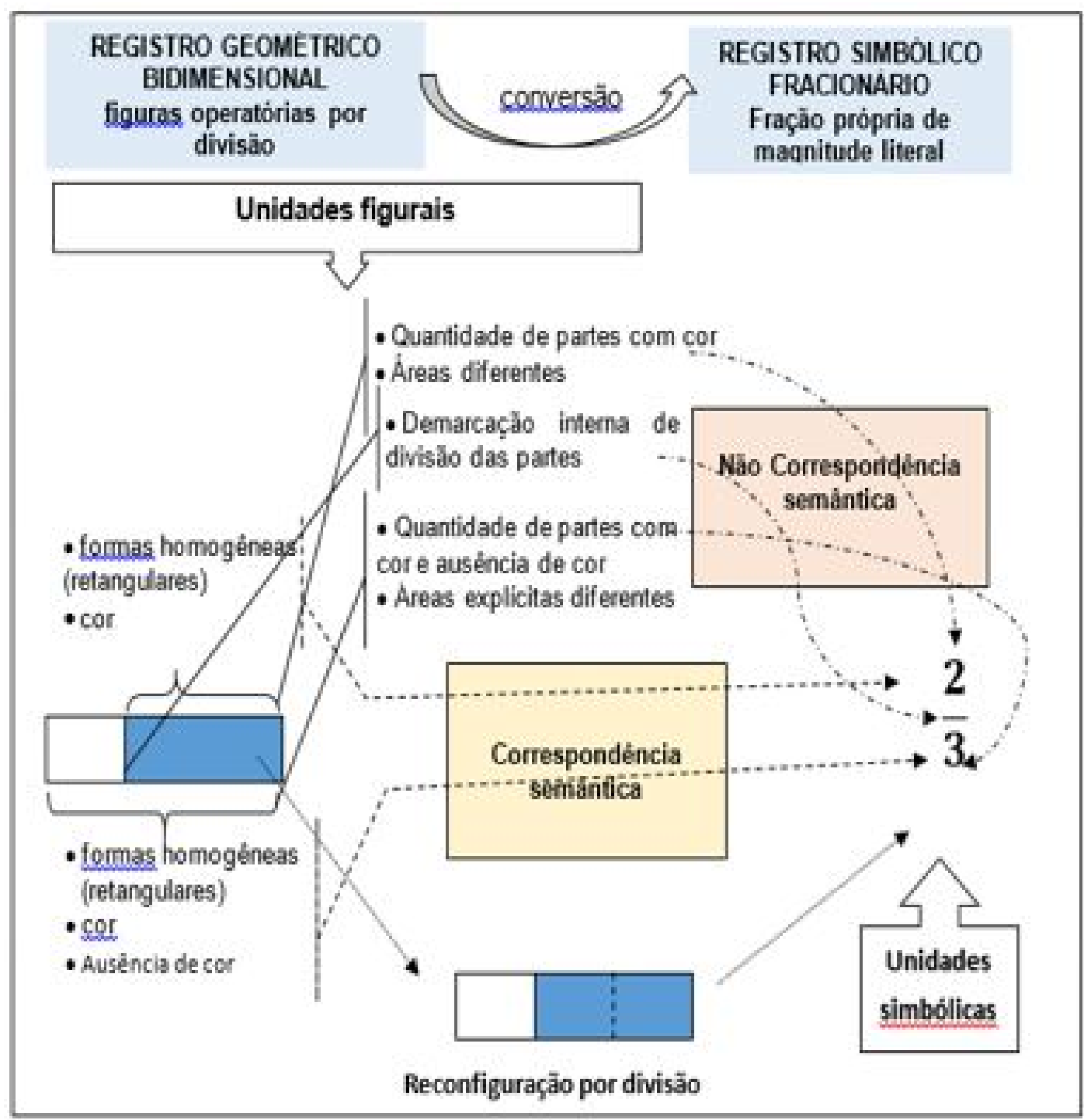

Fonte: [17] (p. 82) 
De acordo com a Figura 6, as unidades figurais, formas geométricas homogêneas das partes ou subfiguras e cor, no registro de partida, correspondem-se semanticamente, de forma combinada, com o numerador da fração, no registro de chegada. $O$ mesmo ocorre entre as unidades figurais, cor, ausência de cor e formas geométricas homogêneas das partes ou subfiguras e o denominador da fração.

As unidades figurais, quantidade de partes ou subfiguras com cor e áreas explícitas diferentes não se correspondem semanticamente com a unidade simbólica, numerador da fração, no registro de chegada; pois o numerador da fração corresponderá ao quantitativo de partes ou subfiguras após o tratamento de reconfiguração por divisão das partes ou subfiguras da figura inicial. Da mesma forma ocorrerá com as unidades figurais, quantitativo de cor e ausência de cor da figura inicial e áreas explícitas diferentes das partes ou subfiguras e o denominador da fração, no registro de chegada. As demarcações internas de divisão do todo não irá corresponder-se semanticamente com o traço de fração, pois a relação das partes com o todo que estabelece na figura inicial não é a mesma entre o numerador e o denominador da fração.

O critério univocidade semântica terminal, como no grau de não congruência semântica anterior, é obedecido entre as demarcações internas de divisão do todo, no registro de partida e o traço de fração, no registro de chegada; e entre as unidade figurais, quantidade com cor e ausência de cor das partes ou subfiguras e a unidade simbólica, denominador.

Entretanto, as unidades figurais, áreas explícitas diferentes das partes ou subfiguras, formas geométricas homogêneas das partes ou subfiguras, cor e quantidade de partes ou subfiguras com cor no registro de partida, não satisfazem o critério da univocidade semântica terminal, pois se correspondem ao mesmo tempo com duas unidades simbólicas, no registro de chegada, numerador e denominador.

[18] aponta para o não reconhecimento da unidade-parte, no momento da conversão entre figuras do tipo operatórias por divisão e a representação fracionária. E, consequentemente, o uso do procedimento da 'dupla contagem', das partes ou subfiguras, sem o reconhecimento da unidade-parte e divisão equitativa da figura geométrica, ou seja, sem considerar que as áreas das partes ou subfiguras da figura geométrica, dadas inicialmente, são explicitamente diferentes.

A operação de reconfiguração intermediária global, explícita ou não, é necessária para particionar a figura inicial em partes ou subfiguras de áreas congruentes. Esse particionamento em unidade-parte, que é uma modificação mereológica, poderá ser feito pela translação de uma parte ou subfigura inicial, escolhida como unidade-parte. A figura final terá um maior número de partes ou subfiguras explícitas, que a figura inicial, conforme Figura 7. 
Figura 7: Operação de reconfiguração das figuras operatórias por divisão.

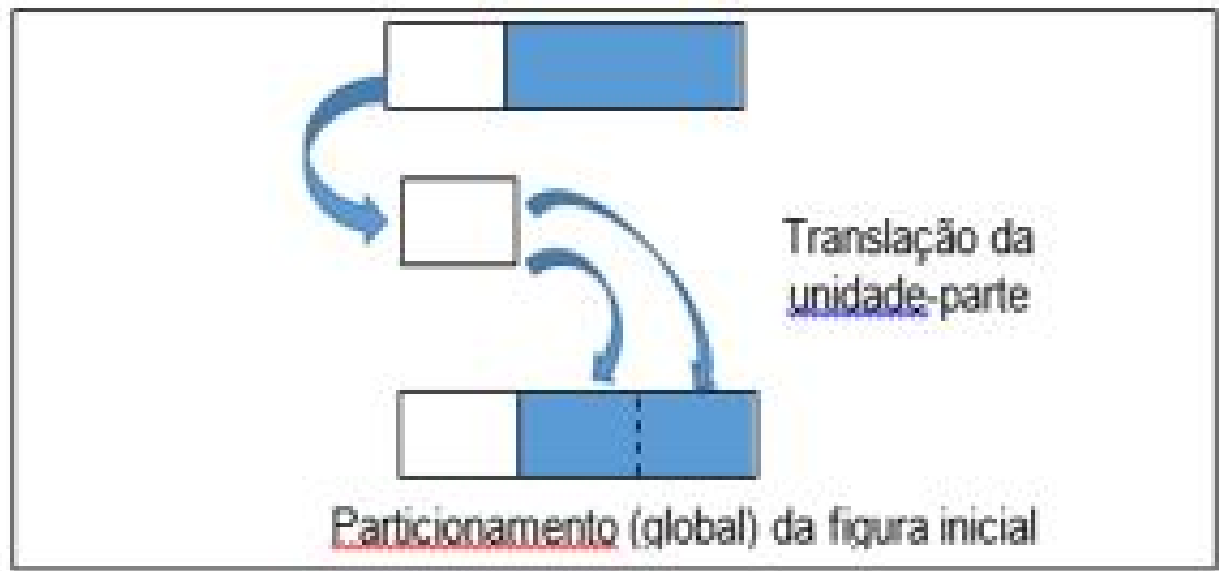

Fonte: [17] (p. 116)

O elemento que torna o tratamento operatório nesses tipos de figuras mais complexo que o anterior, é o particionamento explícito incompleto da figura inicial, que leva ao não reconhecimento imediato da unidade-parte.

\section{GRAU 5 DE NÃO CONGRUÊNCIA SEMÂNTICA}

Nesse nível de não congruência semântica, estarão as conversões que envolvem as figuras operatórias por modificação das formas como registro de partida. Esses tipos de figuras dificultam a apreensão da congruência entre as áreas particionadas, pois elas apresentam formas geométricas diferentes. As figuras operatórias por modificação das formas são polígonos, correspondentes a um inteiro contínuo, dividido em partes ou subfiguras de áreas congruentes e formas heterogêneas, justapostas, sendo algumas delas pintadas ou hachuradas, necessitando um tratamento na figura de desconstrução das formas das subfiguras, explícito ou não, para que as áreas congruentes sejam percebidas e adotadas como unidade de medida para o estabelecimento da relação das partes com o todo, conforme Figura 8.

Figura 8: Operação de reconfiguração das figuras operatórias por divisão.

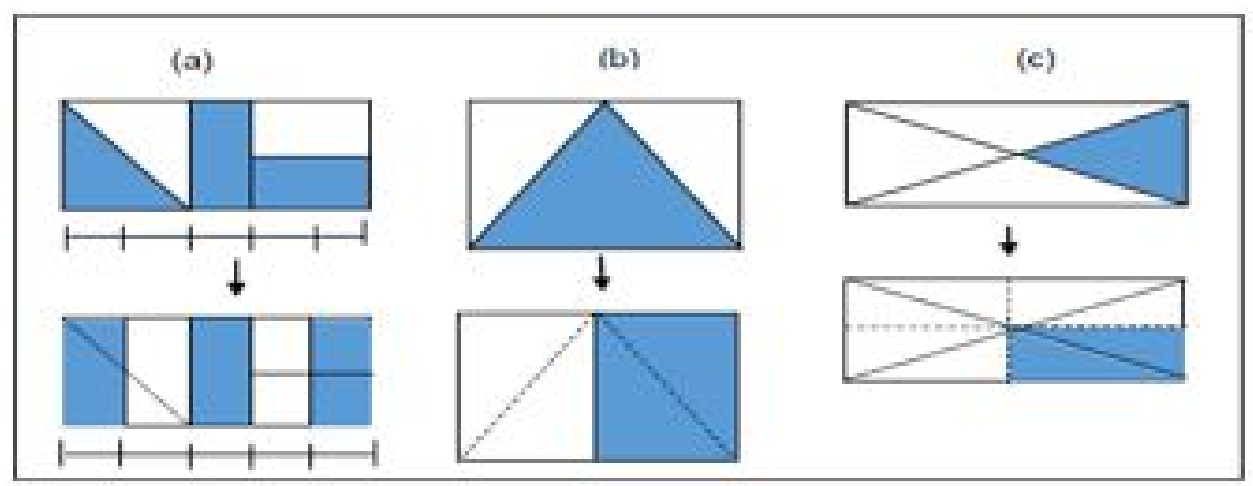

Fonte: (a)(b) [18]; (c) [5] 
Nesse grau, a conversão requer do sujeito além das apreensões, perceptual e discursiva, uma apreensão operatória de reconfiguração, explícita ou não. A operação de reconfiguração pode ocorrer por desconstrução das partes ou subfiguras de formas geométricas heterogêneas e áreas congruentes, e reconstrução dessas em formas geométricas homogêneas de área congruentes.

Esse tratamento permitirá ao sujeito visualizar as subfiguras de mesma área e mesma forma geométrica, possibilitando a compreensão da relação parte-todo para conversão no registro simbólico fracionário.

As unidades figurais do registro de partida são sete: sendo uma unidimensional - as demarcações internas de divisão do todo, contínuo, em partes ou subfiguras justapostas; uma unidade figural bidimensional - as áreas explícitas congruentes das partes ou subfiguras que compõem o todo inicial; as unidades figurais qualitativas - cor ou hachuramento das partes ou subfiguras do todo, ausência de cor, formas geométricas heterogêneas das partes ou subfiguras, quantitativo total das partes ou subfiguras com cor e quantitativo das partes ou subfiguras com cor e ausência de cor, de acordo com a Figura 9. 
Figura 9: Esquema relativo à análise da conversão entre uma figura operatória por modificação das formas do registro geométrico bidimensional dos números racionais e uma fração própria de magnitude literal no registro simbólico fracionário.

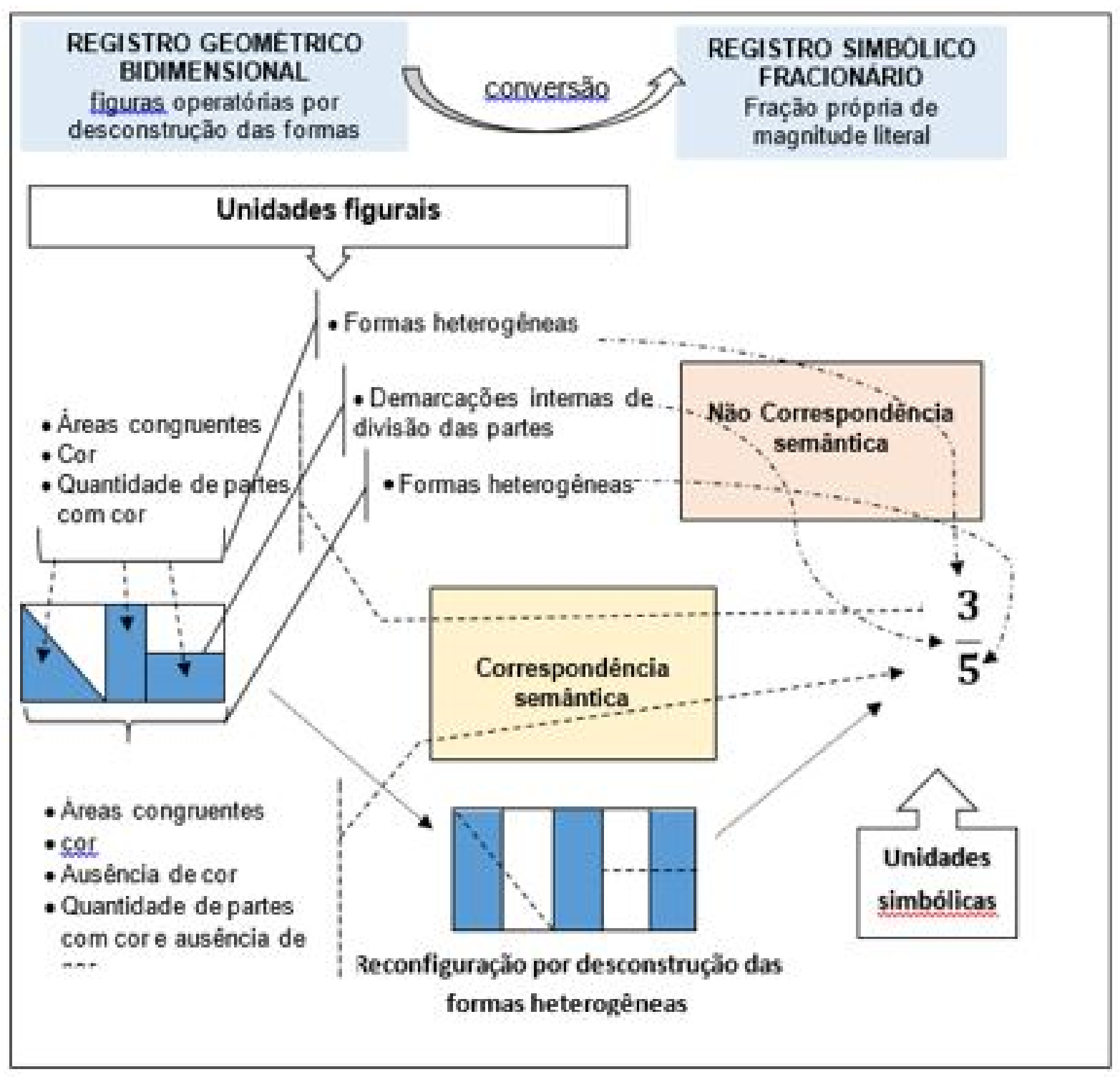

Fonte: [17] (p. 118)

Conforme a Figura 9, as unidades figurais - áreas congruentes, cor e quantidade de partes com cor, no registro de partida - correspondem-se semanticamente de forma combinada, com o numerador da fração, no registro de chegada. O mesmo ocorre com as unidades figurais - áreas congruentes, cor e quantidade de partes com cor e ausência de cor das partes ou subfiguras - e o denominador da fração.

A unidade figural, formas geométricas heterogêneas, não se correspondem semanticamente com a unidade simbólica, numerador da fração, no registro de chegada; pois o numerador da fração corresponderá ao quantitativo de partes ou subfiguras de for- 
mas geométricas homogêneas e mesma área após o tratamento de reconfiguração por desconstrução das formas geométricas heterogêneas da figura inicial. Da mesma forma ocorrerá com a unidade figural, formas geométricas heterogêneas e o denominador da fração, no registro de chegada. As demarcações internas de divisão do todo não irá corresponder-se semanticamente com o traço de fração, pois serão modificadas pelo tratamento na figura inicial, conforme Figura [9].

O critério univocidade semântica terminal, como nos graus de não congruência semântica anteriores, é obedecido entre as demarcações internas de divisão do todo, no registro de partida e o traço de fração, no registro de chegada; e entre as unidade figurais, quantidade com cor e ausência de cor, das partes ou subfiguras e a unidade simbólica, denominador.

Entretanto, as unidades figurais, áreas congruentes das partes ou subfiguras, formas geométricas heterogêneas das partes ou subfiguras, cor e quantidade de partes ou subfiguras com cor no registro de partida, não satisfaz o critério da univocidade semântica terminal, pois se correspondem ao mesmo tempo com duas unidades simbólicas, no registro de chegada, numerador e denominador.

Apesar de ter uma maior quantidade de elementos em correspondência semântica do que os tipos de figuras enquadradas no grau de não congruência semântica anterior, fator que favorece a passagem de um registro a outro; com as figuras operatórias por modificação das formas, o tratamento a ser empregado no registro geométrico, para que sejam visualizadas as unidades figurais relevantes para a conversão no registro fracionário é o de reconfiguração por desconstrução das formas, diferentemente da seção anterior, em que o tratamento a ser adotado no registro geométrico é a reconfiguração por divisão em subfiguras de áreas congruentes.

A heterogeneidade das formas geométricas das partes ou subfiguras do todo, dificultam a visibilidade da congruência das áreas, e a consequente relação parte-todo. A reconfiguração para desconstrução das formas das subfiguras heterogêneas, favorecerá ao sujeito reconhecer a congruência entre as partes ou subfiguras ao transformálas em subfiguras de formas homogêneas.

Por outro lado, com esses tipos de figuras, podemos ter a falsa impressão de que houve o reconhecimento da congruência entre as áreas das subfiguras ou partes, na conversão para o registro simbólico fracionário. O procedimento de contagem das partes hachuradas e das partes total do todo é semanticamente congruente com esse tipo de figura geométrica, pois coincide com o número de partes ou subfiguras pintadas e o número total de partes. A conversão pode ser realizada corretamente usando o procedimento mas sem que o sujeito tenha consciência da conservação da área entre as partes, conforme [5]. 
A operação de reconfiguração intermediária, explícita ou não, é necessária para modificar a figura geométrica inicial, de modo que passe a conter partes ou subfiguras de formas congruentes, mantendo suas áreas iniciais. Essa reconfiguração poderá utilizar um particionamento global e movimentos de rotação e ou translação de partes ou subfiguras, sem modificar a área das partes ou subfiguras iniciais, para transformálas em partes ou subfiguras de formas geométricas homogêneas, como na Figura 10.

Figura 10: Operação de reconfiguração das figuras operatórias por modificação das formas.

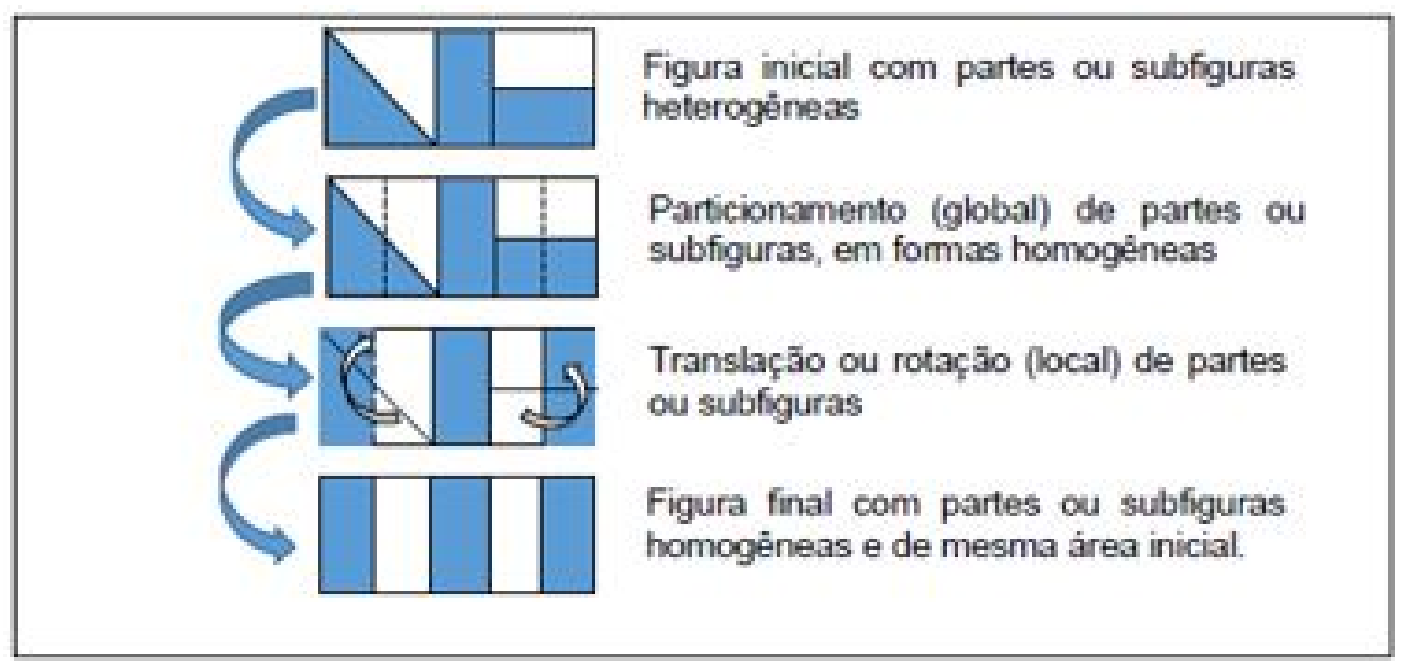

Fonte: [17] (p. 122)

Os tipos de modificações das partes ou subfiguras dependerá da necessidade de cada uma delas, o que pode demandar operações de particionamento global, como também de movimentos de translação e/ou rotação, específicos a esta ou aquela subfigura, sendo assim, operações locais. Essas operações dependerão também, de fatores como a convexidade para a complementaridade de formas.

\section{GRAU 6 DE NÃO CONGRUÊNCIA SEMÂNTICA}

Nesse nível de não congruência semântica estarão as conversões que envolvem as figuras operatórias por modificação das formas e das áreas, como registro de partida. Esses tipos de figuras possuem partes ou subfiguras com áreas e formas geométricas explicitamente diferentes dificultando a apreensão da relação existente das partes com o todo, ou seja, da quantidade de partes ou subfiguras de mesma área que foi dividido o todo e que foram pintadas. As figuras operatórias por modificação das áreas e das formas são polígonos, círculos, correspondentes a um inteiro contínuo, dividido em partes ou subfiguras de áreas diferentes e formas heterogêneas, justapostas, sendo algumas delas hachuradas ou pintadas, necessitando um tratamento no registro, qual seja a análise da relação existente entre as partes não congruentes e entre elas e o todo para desconstrução das formas das subfiguras e reconfiguração do todo na mesma unidade de medida, conforme Figura 11. 
Figura 11: Figuras operatórias por modificação das áreas e das formas.

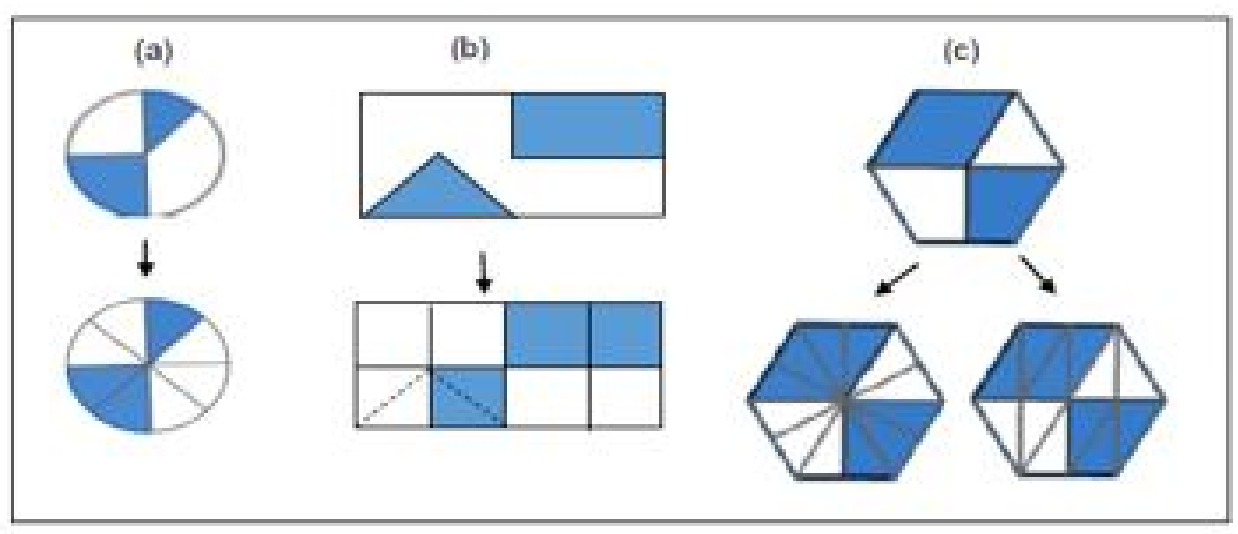

Fonte: (a),(c) [17], 2018; (b) [2]

A conversão requer do sujeito, além da apreensão perceptual das unidades figurais, uma apreensão operatória, de reconfiguração para modificação das áreas e das formas geométricas das subfiguras, explícita ou não, e reconstrução das subfiguras ou partes em áreas explícitas congruentes e formas geométricas homogêneas.

As unidades figurais do registro de partida são sete, sendo uma unidimensional as demarcações internas de divisão do todo, contínuo, em partes ou subfiguras justapostas ou não; uma unidade figural bidimensional - as áreas explícitas diferentes das partes ou subfiguras que compõem o todo inicial; as unidades figurais qualitativas - cor ou hachuramento das partes ou subfiguras do todo, ausência de cor, formas geométricas heterogêneas das partes ou subfiguras, quantitativo total das partes ou subfiguras com cor; e quantitativo das partes ou subfiguras com cor e ausência de cor. Enquanto que as unidades simbólicas do registro de chegada são o número natural que representa o numerador, o traço de fração e o número natural diferente de zero que representa o denominador, conforme Figura 12. 
Figura 12: Esquema relativo à análise da conversão entre uma figura operatória por modificação das áreas e das formas do registro geométrico bidimensional dos números racionais e uma fração própria de magnitude literal no registro simbólico fracionário.

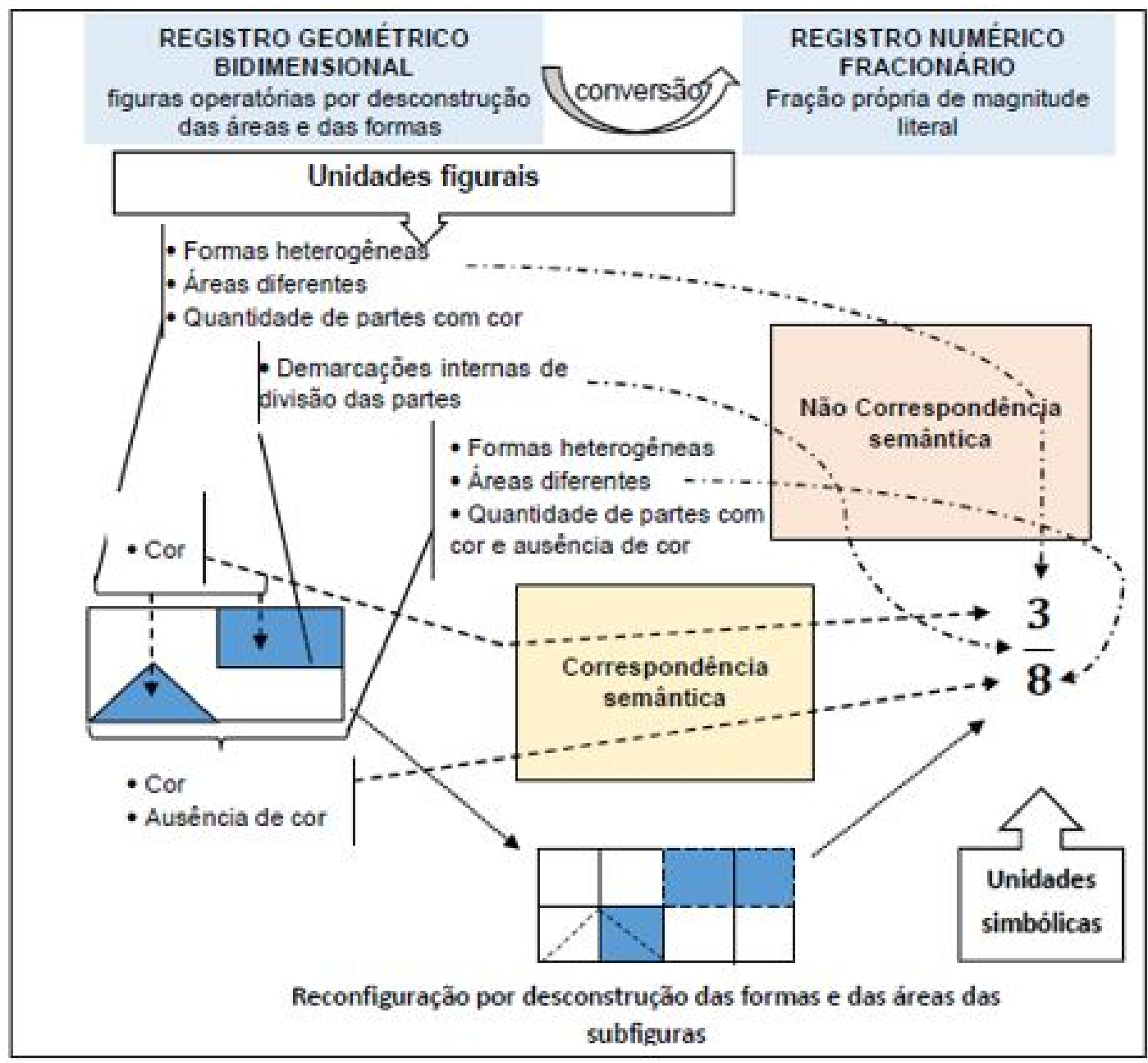

Fonte: [17] (p. 124)

Conforme a Figura 12, a cor é a única unidade figural no registro de partida que corresponde-se semanticamente, de forma combinada, com o numerador da fração, no registro de chegada. O mesmo ocorre entre as unidades figurais, cor e ausência de cor, no registro de partida e o denominador da fração, no registro de chegada.

As unidades figurais, formas geométricas heterogêneas, áreas explícitas diferentes e quantidade de partes com cor não se correspondem semanticamente com a unidade simbólica, numerador da fração, no registro de chegada; pois o numerador da fração corresponderá ao quantitativo de partes ou subfiguras de formas geométricas homogêneas e mesma área, após o tratamento de reconfiguração intermediária. Da mesma forma ocorrerá entre as unidades figurais, formas geométricas heterogêneas, áreas explícitas diferentes e quantidade de partes com cor e ausência de cor e o denominador da fração, no registro de chegada. As demarcações internas de divisão do todo não irão corresponder-se semanticamente com o traço de fração, pois a relação das partes 
com o todo que é estabelecida na figura inicial não é a mesma entre o numerador e o denominador da fração, no registro de chegada.

O critério univocidade semântica terminal continua sendo obedecido entre as demarcações internas de divisão do todo, no registro de partida e o traço de fração, no registro de chegada; e entre as unidade figurais, quantidade com cor e ausência de cor, das partes ou subfiguras e a unidade simbólica, denominador.

As unidades figurais - cor, áreas explícitas diferentes, formas geométricas heterogêneas das partes ou subfiguras e quantidades de partes ou subfiguras com cor e ausência de cor -, no registro de partida, não satisfaz ao critério da univocidade semântica terminal, pois se corresponde ao mesmo tempo com duas unidades simbólicas, no registro de chegada - numerador e denominador.

Podemos observar que a falta de correspondência semântica entre os elementos figurais e os simbólicos é a maior entre os tipos de conversões analisados, sendo a cor e a ausência de cor os únicos elementos figurais que permanecem em correspondência semântica com as respectivas unidades simbólicas. Para a constatação e visualização da relação parte-todo, a figura inicial deverá ser modificada implícita ou explicitamente pela operação de reconfiguração intermediária que poderá envolver as operações de particionamento global; translação e rotação, local, das partes ou subfiguras. Dessa forma, as partes ou subfiguras iniciais com áreas diferentes e formas heterogêneas serão reconfiguradas para conter áreas congruentes entre si e formas homogêneas, conforme Figura 13.

Figura 13: Operação de reconfiguração das figuras operatórias por modificação das áreas e das formas.

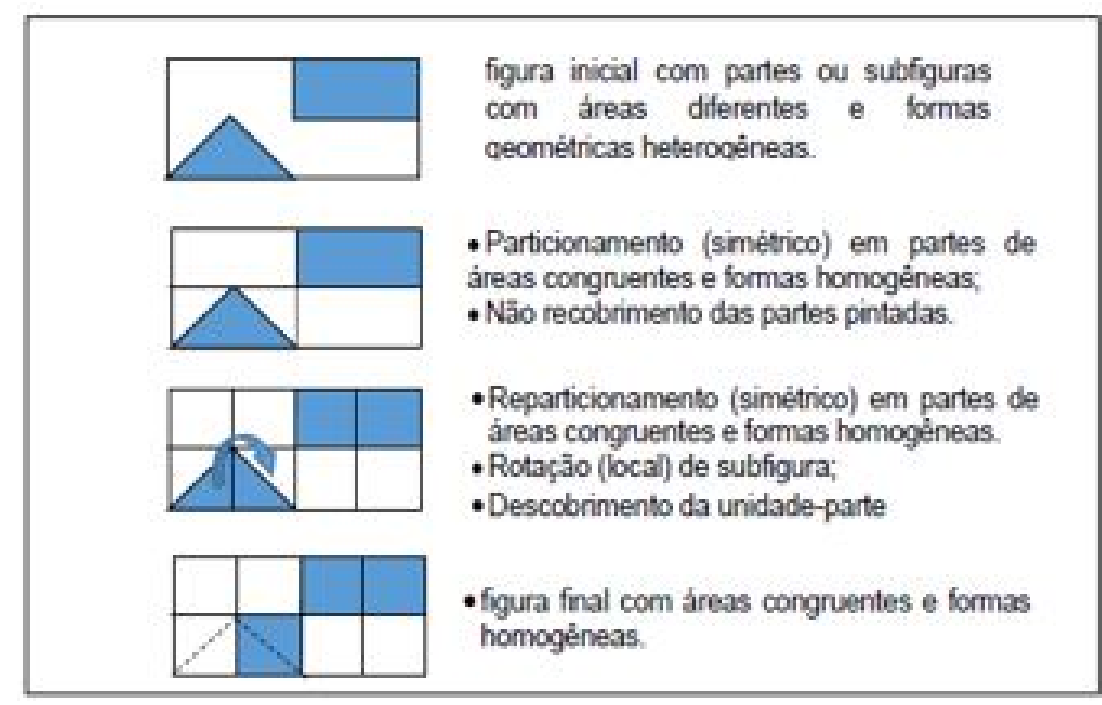

Fonte: [17] (p. 127)

O tratamento figural necessário para a visualização da relação parte-todo, reconfi- 
guração por desconstrução das formas e das áreas das subfiguras ou partes, requer operar tanto de forma global, ou seja, com todas as subfiguras ou partes da figura geométrica, como de forma local - transformando subfiguras específicas, por meio das modificações posicionais de rotação e translação das subfiguras, como no grau anterior. Mas essa reconfiguração poderá acarretar numa figura geométrica totalmente diferente da figural inicial, pois terá subfiguras ou partes com áreas congruentes quando na figura inicial as áreas eram diferentes - e formas homogêneas, ao invés das heterogêneas inicialmente. Dessa forma, poderá guardar apenas, uma relação de semelhança com os contornos fechados dessa figura geométrica. Sendo assim, acreditamos ser essa a modificação mereológica de maior custo cognitivo, em relação aos graus anteriores.

Os resultados encontrados por [2], em que analisou no item 0-35, a conversão para o registro fracionário, tendo como representação de partida, a figura que tomamos como exemplo nessa seção, corroboram com a nossa análise, pois apontam um índice de acertos de apenas 8\% entre 210 alunos de $7^{\mathrm{a}}$ e $8^{\mathrm{a}}$ séries do Ensino Fundamental. Sendo considerado o item mais difícil do teste realizado.

\section{CONSIDERAÇÕES FINAIS}

As conversões entre registros de representações dos números racionais que têm como registro de partida o geométrico bidimensional dos racionais requer fazer corresponder as unidades figurais em duas e uma dimensão com unidades simbólicas do registro de chegada, submetendo-se assim, ao fenômeno da não congruência semântica. A discussão levantada nesse estudo procurou demonstrar as unidades figurais e simbólicas a serem consideradas para cada tipo de figura geométrica envolvida na conversão, como também os tipos de apreensões e critérios de congruência semântica satisfeitos ou não, para mensurar o grau de não congruência semântica nas conversões entre as representações desses registros.

De acordo com [7, 8] o reconhecimento das unidades de sentido a serem postas em correspondência numa atividade de conversão está longe de ser espontâneo. Faz parte dos 'gestos intelectuais' a ser desenvolvidos pelo sujeito na escola. Dessa forma, inferimos que a devida compreensão das conversões entre os registros geométrico bidimensional e simbólico fracionário dos números racionais, e consequentemente, da relação parte-todo no que se refere a esses registros, perpassa pelo trabalho em sala de aula dos seis graus de não congruência semântica categorizados nesse estudo. Sendo assim, propomos que sejam realizadas pesquisas de intervenções em sala de aula, nesse sentido.

Acreditamos também que a categorização em graus de não congruência semântica na conversão entre os registros geométrico bidimensional e numérico fracionário dos 
números racionais, proposta nesse estudo, pode servir como base para a estruturação de propostas pedagógicas, como a produção de sequências didáticas dos livros didáticos de matemática e a implementação de pesquisas envolvendo a engenharia didática que tenham como objetivo o ensino e a aprendizagem do significado parte-todo do número racional na educação básica.

E ainda, observamos que essa pesquisa pode servir de base para a formação inicial e continuada de professores que ensinam matemática tanto nas séries iniciais como nas séries finais do ensino fundamental no que se relaciona às reflexões e discussões sobre a influência da congruência semântica e equivalência referencial nas conversões entre os registros de representações dos números racionais.

\section{REFERÊNCIAS}

[1] M. J. Behr et al. Acquisition of mathematics concepts and processes. New York: Academic Press: Nova York, 1983, p. 91-126.

[2] M. J. Behr, T. Post. The effect of visual perceptual distractors on children's logical-mathematical thinking in rational number situations. In POST, T.; ROBERTS, M. (Eds), Proceedings of the third annual meeting of the North American chapter of the International Group for the Psychology of mathematics education, Mineapolis: University of Minnesota, p. 8-16. 1981. [Google Scholar]

[3] T. Campos; S. Magina; T. Nunes. O professor polivalente e a fração: conceitos e estratégias de ensino. Educação Matemática e Pesquisa, São Paulo, v.8, n.1, p 125-136. 2006. Disponível em: http://revistas.pucsp.br/emp/issue/archive. Acesso em : 02 fev 2017.

[4] W. D. Carraher; A.L. Schliemann. A compreensão de frações como magnitude relativa. Psicologia: Teoria e Pesquisa, v.8, № 1, p. 67-78, 1992. Disponível em: http://www.scielo.br/scielo.php?script= sci_issues\&pid=0102-3772\&lng=en\&nrm=iso. Acesso em: 02 fev 2016.

[5] A. Damico. Uma investigação sobre a formação inicial de professores de matemática para o ensino de números racionais no ensino fundamental. São Paulo, 2007. 313p. Tese (Doutorado em Educação Matemática). Pontifícia Universidade Católica de São Paulo, 2007. [Google Scholar]

[6] R. Duval, Les diferentes fonctionnements d'une figure dans une demarche géométrique. Repères, IREM, 17, p.121-138. 1994. [Google Scholar]

[7] R. Duval, Semiosis y Pensamiento Humano. Registros Semióticos y Aprendizajes Intelectuales. trad. Myriam Veja Rastrepo. Universidad Del Valle. 2004. [Google Scholar]

[8] R. Duval, Ver e ensinar a matemática de outra forma: Entrar no modo matemático de pensar: os registros de representações semióticas. $1^{\text {a }}$ ed. São Paulo: PROEM, 2011.

[9] R. Duval, Diferenças semânticas e coerência matemática: introdução aos problemas de congruência. REVEMAT. Florianópolis, Santa Catarina, v.7, n.1, p. 97-117, 2012a. Disponível em: https://periodicos.ufsc.br/index.php/revemat/issue/archive. Acesso em: 02 fev 2015.

[10] R. Duval, Abordagem cognitiva de problemas de geometria em termos de congruência. REVEMAT. Florianópolis, Santa Catarina, v.7, n.1, p.118-138, 2012b. Disponível em: https://periodicos.ufsc. br/index.php/revemat/issue/archive. Acesso em: 02 fev 2015. [CrossRef]

[11] T. E. Kieren, Five faces of mathematical knowledge building. Edmonton: Department of Secondary Education, University of Alberta, 1981. [Google Scholar] 
[12] V. L. Merlini. O conceito de fração em seus diferentes significados: um estudo diagnóstico com alunos de $5^{\mathrm{a}}$ e $6^{\mathrm{a}}$ séries do Ensino Fundamental. Dissertação (mestrado em Educação matemática) - Pontifícia Universidade Católica de São Paulo, São Paulo, 2005.

[13] W. R. Rodrigues. Números racionais: Um estudo das concepções de alunos após o estudo formal. São Paulo, 2005. 246p. Dissertação (Mestrado em Educação matemática). Pontifícia Universidade Católica de São Paulo, 2005.

[14] A. Santos. O conceito de fração em seus diferentes significados: um estudo diagnóstico junto a professores que atuam no Ensino Fundamental. São Paulo, 2005. 196p. Dissertação (Mestrado em Educação matemática). Pontifícia Universidade Católica de São Paulo, 2005.

[15] L. S. Santos. Análise dos efeitos didáticos emergentes de uma sequência de atividades na aprendizagem do significado parte/todo do número racional. Recife, 2010. 269p. Dissertação (Mestrado em Ensino de Ciências). Universidade Federal Rural de Pernambuco, 2010.

[16] R. S. Santos. Analisando as estratégias utilizadas pelos alunos da rede municipal do Recife na resolução de questões do SAEPE sobre números racionais. Recife, 2011. 119 p. Dissertação (Mestrado em Educação matemática). Universidade Federal de Pernambuco, 2011.

[17] F. A. F. Silva. Graus de não congruência semântica nas conversões entre os registros geométrico bidimensional e simbólico fracionário dos números racionais. Recife, 2018. 258 p. Tese (Doutorado em Ensino de Ciências e matemática). Universidade Federal Rural de Pernambuco, 2018.

[18] M. J. F. Silva. Sobre a introdução do conceito de número fracionário. São Paulo, 1997. 208 p. Dissertação (Mestrado em Ensino da matemática). Pontifícia Universidade Católica. 1997.

[19] R. E. Vizcarra; J. M. G Sallán, Modelos de medida para la enseñanza del número racional em Educación Primaria. UNIÓN, Revista Iberoamericana de Educación Matemática, n 1, p. 17-35, 2005. Disponível em: http://www.fisem.org/www/union/indice_2017.php. Acesso em: 15 mar 2018. [Google Scholar]

\section{BREVE BIOGRAFIA}

Fernanda Andrea F. Silva (D) https://orcid.org/0000-0002-2347-2372

Doutora em Ensino de Ciências e Matemática pela Universidade Federal Rural de Pernambuco. Professora da Educação Básica Técnica e Tecnológica do Instituto Federal da Paraíba - IFPB, Campus Cajazeiras. Integrante do grupo de pesquisa Fenômenos Didáticos na classe de matemática e do grupo de Pesquisa Didática da matemática e Semiótica e do Grupo Cajazeirense de Pesquisa em Matemática.

Marcelo Câmara dos Santos (D) https://orcid.org/0000-0002-6466-9040

Doutor em Sciences de L'education - Université de Paris X, Nanterre. Professor dos Programas de Pós-graduação em Educação Matemática e Tecnológica da UFPE, do Programa de PósGraduação em Ensino das Ciểncias da UFRPE e do Programa de Pós-graduação Profissional em Gestão e Avaliação da Educação da UFJF. 